\title{
A Commentary on the Drug Addiction Treatment Market in Iran
}

\author{
Saeed Nateghi ${ }^{1}$ and Hosein Effatpanah ${ }^{2, *}$ \\ ${ }^{1}$ School of Medicine, Ziaeian Hospital, International Campus, Tehran University of Medical Sciences, Tehran, Iran \\ ${ }^{2}$ Department of Public Health, Asadabad School of Medical Sciences, Asadabad, Iran \\ "Corresponding author: Department of Public Health, Asadabad School of Medical Sciences, Asadabad, Iran. Tel: +98-9123787394, Email: m.effatpanah@gmail.com
}

Received 2020 May 20; Revised 2020 June 10; Accepted 2020 July 11.

Keywords: Addiction, Drug Dependence, Opioid Substitution Treatment

\section{Dear Editor,}

Illicit drug use is associated with multiple risks of harm to the users, their families, and social network in Iran, the most populous Persian Gulf country (1-3). A paper by Rezaee et al. (4) about newspaper advertisements related to drug treatment services in Iran has been recently published in the Iranian Journal of Psychiatry and Behavioral Sciences. The paper is important because drug treatment advertisements show the trend of demand for treating illicit drug use in Tehran, the capital city of Iran (4).

Rezaee et al. (4) conducted a study in 2009 and another one in 2012 to review published advertisements in a large number of newspapers in Tehran. In 2009, 66 drug treatment centers advertised professional services. Three years later, in 2012, 99 drug treatment clinics advertised their services, which showed a remarkable increase (i.e., 33\%). Based on the results, methadone treatment was found to be the most common treatment modality in Tehran (i.e., 85\%). In 2009, there was no notice regarding MA in the advertisements, but in 2012, approximately $43 \%$ of the centers included the related notice in the published advertisements, showing the business reaction to the increasing MA problem in the Persian community (4).

In this study, the drug addiction market referred to drug treatment services in the community, such as methadone treatment (4) The study includes two key points. First, a few studies have investigated the trend of published advertising of drug treatment services in Iran. The second important key point is that the findings show how advertisements made a crucial transition from opiate treatment in 2009 to opiate and MA treatment in 2012. This finding is important because it highlights how the traditional illicit drug market in Iran made a transition from opiates to highly addictive MA. This finding is consistent with a series of newly-published papers in Iran, which indicate how MA has become a critical health problem among a large proportion of opiate users $(1-3,5)$. This finding has important treatment implications for health policy-makers and clinicians in Iran to pay attention to the MA problem in the community.

However, Rezaee et al. (4) [U+02BC] study has several important key points to investigate, as follows:

1) The study was limited to Tehran, the capital city of Iran. Therefore, the study findings may not be representative of the whole country. A larger study needs to be conducted to investigate the trend of drug treatment advertising in all parts of Iran;

2) The sample size does not include online drug treatment advertising. However, online drug treatment advertising may not be ignored. A larger study including all printed newspapers and online drug treatment advertisements is needed to investigate this trend;

3) Psychotherapy has remained an important part of drug treatment in Iran (6-8). Studies indicate that general health promotion also remains a key aspect of increasing psychological well-being (9-11). However, the current study has no emphasis on advertising health promotion and psychological services as part of drug treatment in Iran and;

4) The positive and negative aspects of drug treatment advertising and the effects of advertising on treatment entry were not well-investigated in the present study. Therefore, a qualitative study also needs to be conducted to investigate these issues by asking service providers in drug treatment clinics.

In our view, Rezaee et al.' (4) study is a novel and important investigation that aimed to identify and examine an important health issue in the Persian context. Obviously, some opiate- and/or MA-using patients may enter drug treatment due to the sufficient availability of published advertisements.

As a new study in Iran, the paper benefits the service providers and drug researchers by providing a summary 
of the existing evidence in the drug treatment business in Iran. As the authors suggested, longitudinal trend analyses of published advertisements, as a flexible strategy, will present a detailed profile of drug treatment services. It will display that drug treatment continues its services in the market based on the new demands in the community like the new epidemic MA problem in Iran.

\section{Footnotes}

Authors' Contribution: All authors have contributed to writing, editing, and revising this letter.

Conflict of Interests: There is no conflict of interest.

Funding/Support: No funding is reported.

\section{References}

1. Sami S, Effatpanah M, Moradi A, Massah O. Matrix model as an intensive rehabilitation in three methadone services in Iran. Iran Rehabil J. 2017;15(3):293-8. doi: 10.29252/nrip.irj.15.3.293.

2. Dana S, Effatpanah M, Mahjoub A. The new epidemic problem of psychoactive drugs at drug treatment centers of Iran: Implications for education, prevention and treatment. Iran J Psychiatry Behav Sci. 2018;12(2). doi: 10.5812/ijpbs.63555.

3. Rafiey H, Ghaderi S, Morovat B, Noori R, Effatpanah M, Mahjoub A et al. Amphetamine type stimulants use in the adult population of tehran: Implications for long term rehabilitation. Iran Rehabil J. 2017;15(4):303-8. doi: 10.29252/nrip.irj.15.4.303.
4. Rezaee S, Esmizadeh S, Deilamizade A, Norouzi A, Ekhtiari H. A trend study on media representation and economic circulation of drug addiction treatment market in Iran: Development of opioid maintenance services and emergence of treatment menu for amphetamines. Iran J Psychiatry Behav Sci. 2019;In Press(In Press). doi: 10.5812/ijpbs.66885.

5. Tavakoli M, Effatpanah M, Moradi A, Mahjoub A. Methamphetamine dependence among Iranian female methadone patients: A crosssectional survey of three cities of Iran. Iran J Psychiatry Behav Sci. 2018;12(2). doi:10.5812/ijpbs.62866.

6. Effatpanah M, Rezaei M, Effatpanah H, Effatpanah Z, Varkaneh HK, Mousavi SM, et al. Magnesium status and attention deficit hyperactivity disorder (ADHD): A meta-analysis. Psychiatry Res. 2019;274:228-34. doi: 10.1016/j.psychres.2019.02.043. [PubMed: 30807974].

7. Shakiba K, Effatpanah M, Moradi A. Cognitive-behavioral therapy for methamphetamine dependence among methadone-maintained patients. Iran J Psychiatry Behav Sci. 2018;12(2). doi:10.5812/ijpbs.63615.

8. Salimi S, Effatpanah M, Mahjoub A. Motivational interviewing can facilitate entry to matrix treatment for methamphetamine dependence. Iran J Psychiatry Behav Sci. 2018;12(2). doi: 10.5812/ijpbs.63560.

9. Khoramizadeh M, Effatpanah M, Mostaghimi A, Rezaei M, Mahjoub A, Shishehgar S. Treatment of amphetamine abuse/use disorder: A systematic review of a recent health concern. Daru. 2019;27(2):743-53. doi: 10.1007/s40199-019-00282-3. [PubMed: 31228128]. [PubMed Central: PMC6895313].

10. Effatpanah M, Moradi A. Methamphetamine dependence and technology-based interventions in Iran. Iran J Psychiatry Behav Sci. 2018;12(2). doi: 10.5812/ijpbs.62935.

11. Sharifi V, Bakhshaie J, Hatmi Z, Faghih-Nasiri L, Sadeghianmehr Z, Mirkia S, et al. Self-reported psychotic symptoms in the general population: Correlates in an Iranian urban area. Psychopathology. 2012;45(6):374-80. doi:10.1159/000337749. [PubMed: 22854278]. 